\title{
Duas vezes Lopes + Zigrino: três experiências com máscara no Brasil
}

\author{
Felisberto Sabino da Costa
}

o findar a Segunda Guerra Mundial, o trabalho com a máscara na Europa não sofre mais solução de continuidade, estabelecendo-se um enredado que insere mais fortemente o Brasil a partir dos anos 80 . O encontro de Jacques Lecoq, Amleto Sartori, Dario Fo, Gianfranco de Bosio e Giorgio Strehler, entre outros, dá-se numa atmosfera permeada pela máscara, e a importância dessas conexôes reside no olhar com que ela é vista. Não lhes interessava o seu resgate pelo viés museológico, mas trazê-la para aquela realidade, inserindo-a em uma ambiência em que o corpo e o objeto respondiam aos anseios e inquietações do seu tempo. No ambiente acadêmico, o trabalho se dá por meio da experiência de Lecoq na Universidade de Pádua. Posteriormente, a convite de Strehler e Paolo Grassi, Lecoq dirige-se a Milão, onde participa da criação da Escola do Piccolo Teatro. É dessa época também o seu contato com Dario Fo, formado pela Escola de Belas Artes de Milão.

Em paralelo a essas experiências, outros artistas-professores, muitos dos quais oriundos do Vieux Colombier, realizavam trabalhos a partir de diferentes perspectivas, na França, e depois em outros países. A título de ilustração, podemos citar Jean Dasté, Michel Saint-Denis,
Leon Chancerel entre outros. Ao criar a escola do Vieux Colombier, Copeau tinha como objetivo inicial formar atores para a sua companhia. $\mathrm{O}$ diretor-pedagogo tencionava desenvolver em seus alunos qualidades técnicas e éticas, em que o coletivo fosse o suporte, uma vez que se tornar ator pressupunha também ser portador de uma cultura geral. Distanciando-se da prática em que o ator é uma "cabeça falante", a pedagogia de Copeau privilegia o trabalho corporal que traduza uma atitude interior e, sob esse aspecto, a máscara pedagógica converte-se em um instrumento valioso. $\mathrm{O}$ método propunha que se partisse do silêncio para a fala, e esta resultava da ação e da percepção interna da sua necessidade. De igual modo afeito ao universo da máscara, outro fundamento que constitui a base da aprendizagem é a observação dos jogos da infância naquilo que eles têm de lúdico e espontâneo.

Com o retorno de Jacques Lecoq a Paris, e com a fundação de sua escola em 1956, temse o início de uma experiência que se espraiou para diversas partes do planeta, constituindo-se uma base para outras que a sucederam. Assim, os trabalhos desenvolvidos pelas professoras Maria Helena Lopes (UFGRS) e Elizabeth Lopes (Unicamp), bem como pelo artista-pedagogo italiano Francesco Zigrino, a partir da primeira

Felisberto Sabino da Costa é professor do Departamento de Artes Cênicas da ECA-USP. 
metade da década de oitenta do século passado, têm referências na metodologia de Lecoq e contribuíram para fomentar a linguagem cênica e a pedagogia da máscara em nosso país.

\section{Jacques Lecoq: da máscara neutra ao clown}

$\mathrm{Na}$ passagem que Lecoq denomina "a viagem pessoal”, ele nos diz que fora convidado a trabalhar na Universidade de Pádua, para ensinar movimento e improvisação. Nessa cidade, decide continuar o trabalho com a máscara nobre ${ }^{1}$ (por ele definida como neutra), que o havia influenciado quando do seu contato com os Comédiens de Grénbole. Inicialmente confeccionada segundo a técnica aprendida com Jean Dasté, ${ }^{2}$ é a partir do seu contato com Amleto Sartori $^{3}$ que resulta a elaboração da máscara neutra e a sua feitura em couro.

Após a "aventura italiana” que se estende por oito anos, Lecoq regressa a Paris, levando consigo duas descobertas (cf. Lecoq, 1997, p. 21): a commedia dell'arte e o trabalho com o coro da tragédia grega que, juntamente com a máscara neutra, expressão corporal, pantomima branca, figuração mimada, máscaras expressivas, música, acrobacia dramática e mimo de ação, compóem o programa inicial de sua escola. De- pois, foram se agregando outras técnicas como, por exemplo, a busca do próprio clown e as máscaras larvárias, na sua forma branca - antes da pintura que nelas é realizada para a festa de carnaval de Basiléia (Suíça).

Fundamentalmente, a metodologia de Lecoq baseia-se no seguinte postulado: "como as coisas se movem e como refletem em nós". O eixo norteador da pedagogia é a "viagem do silêncio à palavra", e desenvolve-se em dois anos, entre a atuação e a improvisação, por um lado, e o estudo do movimento (técnica e análise), por outro, constituindo um duplo caminho que é complementado com as criações pessoais dos próprios alunos.

O primeiro ano tem início com a atuação psicológica silenciosa, em que Lecoq valese do conceito de "rejeu" (re-jogo), no qual busca resgatar o universo da criança, ou seja, voltar ao espírito lúdico, à brincadeira, por intermédio do jogo dramático. Nesse momento, não há a preocupação com o público, que aparecerá posteriormente na atuação, quando o ator, consciente da dimensão teatral, "dá uma forma à sua improvisação" (Lecoq, 1997, p. 41). O "rejeu”, para Lecoq, é o momento em que a recreação torna-se (re) criação, "é fazer com que o ator reencontre a liberdade de movimento que predomina na criança antes que a vida social imponha outros comportamentos" (id., ibidem). A

1 O começo da vida profissional de Jacques Lecoq se deu em 1945, na companhia Comédiens de Grénoble, dirigida por Jean e Marie-Hélène Dasté, retomando em parte Copeau, o espírito dos copiaux, e buscando um público popular com um teatro simples e direto. Lecoq entrou em contato com o jogo da máscara por intermédio das encenações $O$ Exxodo, figuração mimada com a máscara nobre, e $O$ que murmura o rio Sumida, uma peça Nô em que os atores mimavam os movimentos de um barco enquanto vozes evocavam sons de um rio (cf. Lecoq, 1997).

2 Basicamente, a técnica consistia na modelagem da máscara em argila e, depois de retirado um negativo em gesso, em confeccionar a máscara nesse molde por meio da aplicação de camadas de papel e cola.

3 Conforme Lecoq, foi ele quem apresentou Sartori a Strehler, para quem elaborou as máscaras para a encenação de Arlequim Servidor de dois Amos. A peça já havia estreado, porém, os atores utilizavam máscaras de papel machêe e maquiagem-máscara. Apaixonado pela máscara, durante a Segunda Guerra Mundial Strehler trabalha em Genebra, onde realiza, com refugiados de língua francesa, uma montagem da peça Assassinato na Catedral, de T. S. Elliot, utilizando máscaras planas. 
partir desse passo inicial, investigam-se "as dinâmicas da natureza”, em que os elementos materiais, as cores, os animais, as luzes, os sons e as palavras são (re) conhecidos pelo corpo do ator, prática que serve à composição dos personagens. A dinâmica do movimento é trabalhada a partir do corpo em ação, no qual se (re)conhecem as leis que a constituem, tendo como base, essencialmente, três manifestações naturais: a ondulação; a ondulação inversa e a eclosão. ${ }^{4}$ Para Lecoq, "o mimo de ação nos leva a descobrir que tudo o que faz o homem em sua vida pode resumir-se a duas ações essenciais: empurrar e puxar", e esses dois procedimentos (com suas variações) estão na base dos territórios dramatúrgicos.

No segundo ano da "viagem", a "geodramática" experimenta os caminhos da criação, que têm início com as linguagens do gesto (Pantomima e História Mimada) e encerram-se com a exploração das seguintes extensões dramáticas: melodrama (sentimentos), commedia dell'arte (comedia humana), bufōes (grotesco e mistério), tragédia (o coro e o herói) e o clown (burlesco/absurdo). O coro trágico, conforme observa, "é a multidão elevada ao nível da máscara" (Lecoq, 1997, p. 139).

$\mathrm{Na}$ escola de Lecoq, a máscara tem, basicamente, duas funções: uma teatral e outra pedagógica. Com a linguagem da máscara, busca-se trabalhar o potencial expressivo do corpo - que, sob a máscara neutra, está em estado de suspensão - e territórios cênicos. $\mathrm{O}$ ensino se dá pela via negativa: não se indica ao aluno o que deve fazer e, para o observador, não se trata de opinar, mas de constatar. No percurso que se estende da máscara neutra ao clown, cultiva-se o treino do olhar para a leitura justa do movimento.

\section{O território da máscara no Brasil: três experiências multiplicativas}

Como visto acima, a partir de seu resgate no século XX, o trabalho com a máscara em escolas de teatro insere-se em uma perspectiva estética e pedagógica e a partir da década de 80 , verifica-se um impulso no Brasil, tanto no que se refere à formação do ator quanto à exploração da linguagem. Nesse período, há o retorno de professores e artistas que foram estudar no exterior e, ao regressarem, contribuem para a disseminação de um trabalho mais sistemático. A tradição européia, principalmente a francesa e a italiana, é a principal referência, e mesmo a vertente americana que aqui aportou é tributária das escolas européias. Soma-se ao retorno, a chegada de pesquisadores, artistas e companhias teatrais que contribuem para a discussão, a divulgação e a multiplicação dessa linguagem. Além das escolas, ou de equipes vinculadas a instituições, surge no seio dos grupos de teatro autônomos um espaço de criação, de investigação e de formulação de uma pedagogia. Nesse segmento, o Théâtre du Soleil destaca-se como a principal referência, aliando trabalho artístico e prática político-pedagógica.

Nesse período, as professoras Maria Helena Lopes e Elizabeth Lopes, após passarem por experiências no exterior, estão entre as primeiras a introduzir o trabalho prático com a máscara em universidades brasileiras. Formada pela ECA/USP, em 1974, Elizabeth Lopes é autora da primeira tese de doutorado sobre o assunto, defendida em 1990, na Unicamp. Concluído o curso de graduação, embarca para os Estados Unidos, para fazer mestrado em direção teatral na State University of New York (SUNY), em Albany. Nessa cidade, mantém contato com o

4 A ondulação seria o primeiro movimento do corpo humano e de todas as locomoçôes, como, por exemplo, o andar, que compõe uma multidão saindo de um metrô. A ondulação inversa partiria de um móvel exterior ao corpo e a eclosão está ligada à relação comprimir/expandir. 
grupo de teatro Black Ensemble, especializado em clown e em commedia dell'arte. Entusiasmada por essa experiência prática, Lopes decide ir à África, no intuito de observar a cultura dos povos Dogon, para pesquisar o fenômeno da possessão por intermédio das máscaras. De regresso ao Brasil, realiza trabalhos em commedia dell'arte, e retorna à França, para estudar antropologia, com a qual buscava subsídios para embasar a sua prática. Permanece em Paris durante dois anos, período em que realiza um estágio com Mário Gonzalez, ex-ator do Théâtre du Soleil e professor de máscaras no Conservatório Nacional Superior de Arte Dramática (CNSAD). ${ }^{5} \mathrm{O}$ método utilizado por Gonzalez tem suas raízes na Escola de Jacques Lecoq, onde foi aluno e professor. Ao desligar-se da Escola, desenvolve um trabalho próprio, a partir das bases do seu antigo mestre.

Quando retorna de uma outra estada em Albany, Lopes é convidada pelo diretor Celso Nunes, seu antigo professor na ECA, a integrar o Departamento de Artes Cênicas da Unicamp, como professora de máscaras. Inicia a sua trajetória nessa Universidade em 1987, lá permanecendo quatro anos. Na Unicamp, emprega uma metodologia baseada no "transe controlado", desenvolvida a partir de pesquisa própria e do trabalho de Keith Johnstone. O método tem por objetivo "a formação de atores com máscara, visando não ao teatro mascarado, não ao transe, mas sim a um suporte sólido para o ator, a fim de que ele possa abandonar a máscara (objeto concreto) e abordar, com muito mais segurança, a máscara metafórica dos personagens que vai representar ao longo de sua carreira profissional" (Lopes, 1990, p. 12). Lopes elabora o seu percurso, fundamentalmente, com a junção de técnicas originárias da escola de Copeau e a experiência de Keith Jonhstone, como subsídio para a compreensão do "transe controlado" em sala de aula. Quanto às referências metodológicas, conta ainda com profissionais americanos e europeus que passaram pela escola de Jacques Lecoq. No ritual de iniciação à máscara, reelabora os procedimentos de Jean Dorcy e de Saint-Denis, quando este se refere ao uso do espelho. $\mathrm{Na}$ indução ao "transe hipnótico", que funciona também como elemento de concentração, a professora não permite que os alunos permaneçam sozinhos. Como Johnstone observa, o transe precisa ser controlado pelo professor em sala de aula, o aluno não pode portar a máscara de forma isolada (cf. Johnstone, 1981, p. 167). Para Elizabeth Lopes, em decorrência da herança africana no Brasil, um componente expressivo sobre a possessão permeia nossa cultura, haja vista os rituais de umbanda e do candomblé (cf. Lopes, 2004).

A disciplina era ministrada durante dois semestres letivos, partindo do silêncio para a fala, iniciando-se com a máscara neutra, depois meia-máscara neutra, máscara expressiva e finalizando com as máscaras da commedia dell'arte. Na meia-máscara neutra - também utilizada no Vieux Colombier - poderia haver a inclusão da sonoridade. A abordagem da commedia dell'arte tem como base os procedimentos utilizados por Philippe Hottier, ex-integrante do Théâtre du Soleil, quando estabelece a relação das linhas da máscara com corpo do ator. Segundo Hottier, uma vez sobre o rosto, a máscara é o corpo inteiro que representa, e no objeto estão inscritas a energia mental e física do personagem (cf. Hottier, 1989, p. 235). Assim, ele transpõe essas linhas de energia para o corpo, situando as que formam o nariz da máscara na extremidade inferior do osso externo. Neste

5 Gonzalez ingressa no Conservatório (CNSAD) em 1981. Natural da Guatemala, no início de sua carreira trabalhou com teatro de bonecos. Em Paris, integra o Théâtre du Soleil, durante oito anos, participando dos espetáculos Les Clowns, em que fez o papel de Pépé la Moquete, 1789 e L'Âge d'Or. Em 1989, funda a Companhia Mário Gonzalez, e exerce a função pedagógica em diversos países do mundo. 
sentido, para o personagem Pantallone (Pantaleão), o ponto culminante do nariz situa-o na base do referido osso, e as arcadas supracialiares são relacionadas aos ombros, direcionando-os para trás. Contrapondo-se a esse vetor, a bacia tende a ir para frente, fazendo com que haja uma flexão nas pernas. A voz do personagem surge dessa organização corporal, cuja dificuldade leva-a a ter uma característica própria em virtude da respiração. $\mathrm{O}$ mesmo processo é aplicado às demais máscaras, nas quais "a posição do corpo modifica as percepções do pensamento" (Hottier, 1989, p. 236), contribuindo para a composição do personagem.

Considerando-se tributária da pesquisa iniciada por Jacques Copeau, Lopes diz distanciar-se da "postura cartesiana" de Jacques Lecoq, "que enfatiza as regras e técnicas, mantendo certo distanciamento professor-aluno" (Lopes, 2004). Porém, mesmo que por via indireta, há pontos de contato com o trabalho de Lecoq. Atualmente, Elizabeth Lopes centra sua pesquisa na linguagem do clown, tendo abandonado, momentaneamente, o trabalho com as outras modalidades de máscaras envolvendo o transe controlado. Este torna-se algo complexo quando se trabalha numa perspectiva em que o ator deva ter consciência da sua presença em cena.

Corpo e movimento são primordiais na pedagogia de Maria Helena Lopes, tanto como diretora quanto professora. Em 1967, ingressa no Curso de Artes Cênicas da UFRGS, ${ }^{6}$ e trabalha como docente até o início dos anos 90, quando se aposenta. O seu primeiro contato com a máscara, como instrumento para a formação e o treinamento do ator, foi por meio de um estágio promovido por Jacques Lecoq. Movida por essa experiência, decide cursar o primeiro ano da Escola, em 1979, período duran- te o qual aprofunda o contato inicial com as máscaras de trabalho, principalmente, a máscara neutra, as máscaras utilitárias e as máscaras larvárias. Os princípios que constituem essa linguagem são postos em ação, em diversos procedimentos, como, por exemplo, instaurar o jogo a partir das impressōes que uma máscara produz em outra. $\mathrm{O}$ olhar mútuo afeta o corpo-mente daquele que veste a máscara, alimentado por um fluxo de mão-dupla, em que as (im)pressões colhidas reverberam e geram as fricções que alimentam o improviso. Segundo a diretora-pedagoga, interessava-lhe obter o conhecimento da linguagem e aplicá-lo na Escola de teatro da UFRGS (cf. Lopes, 2006).

Da viagem pedagógica proposta por Lecoq, Maria Helena Lopes manteve o ponto de partida e o de chegada; os recursos utilizados entre um e outro pólo, contudo, sofriam variaçôes. Durante sua permanência na França, trabalhou outras formas de máscaras que propiciaram o desenvolvimento de sua metodologia. ${ }^{7}$ Nesse sentido, a utilização de determinados objetos, ligeiramente ou bastante modificados, resultava em configuraçōes expressivas no território da máscara. É nessa linha que se situa, por exemplo, o trabalho com máscaras elaboradas com garrafas plásticas de água.

No início dos anos 80, quando introduz o trabalho no Departamento de Arte Dramática (DAD), as máscaras tornam-se instrumentos valiosos, no exame dos múltiplos aspectos da improvisação. O percurso iniciava no segundo semestre do primeiro ano, quando realizava algumas inserçôes com a máscara neutra. Nos dois semestres do ano seguinte, a exploração com a máscara neutra estava plenamente desenvolvida, bem como as abordagens com as outras modalidades.

6 Atualmente, chama-se Departamento de Arte Dramática (DAD) do Instituto de Artes. Maria Helena foi professora de Interpretação, Improvisação, Expressão Corporal e Direção.

7 Entre outros, Maria Helena trabalhou com Serge Martin, ator e diretor francês. Martin ensinou na Escola de Jacques Lecoq e na Universidade de Caen. 
Quanto à fatura do objeto-máscara, a professora procurava fazer com que os próprios alunos o confeccionassem. Geralmente, elaborado com papel e cola, buscava-se nesse objeto uma feição destituída de traços particulares. Além das restrições financeiras para obtenção de máscaras de couro, Lopes observa que

não era muito o caso de ficar repetindo um mesmo modelo. Eu precisava de uma máscara suficientemente neutra, mas que não fosse, necessariamente, a da Escola de Lecoq, até porque para obter as máscaras de couro, era muito complicado. O importante era a máscara ter uma sensibilidade e eles conseguiam resultados que se aproximavam bastante da idéia de máscara neutra desenvolvida na Escola de Jacques Lecoq (Lopes, 2006).

Em 1981, ao fundar o grupo Tear, Maria Helena alia criação artística e pedagogia, procedimento ao qual se alinha, nos anos seguintes, os grupos Fora do Sério (Ribeirão Preto-SP), Barracão (Campinas-SP), Amok (Rio de Janeiro-RJ) e Moitará (Rio de Janeiro-RJ). No Tear, a diretora emprega as máscaras de trabalho, como estágio necessário à máscara do clown, recurso imprescindível para a constituição do clown almejado. A montagem de Os Reis Vagabundos (1982) repousa numa pesquisa sobre catadores de lixo, levada à cena com a linguagem do clown. ${ }^{8}$

Maria Helena Lopes trabalha a máscara como objeto teatral, buscando a sensibilidade e a percepção necessárias ao aluno para vestir uma máscara, criando um estado favorável ao jogo. Todavia, não é sempre que utiliza a máscara: isso ocorre de forma pedagógica, quando oferece cursos, ou quando trabalha com um grupo de atores que vão constituir o seu elenco. A máscara pode ser um instrumento tanto para o ator, que não vai necessariamente utilizar aquela linguagem, quanto para aquele que a toma como expressão, principalmente o clown.

Enquanto as professoras Elizabeth Lopes e Maria Helena Lopes foram em busca de aperfeiçoamento no exterior, na via de mão dupla que sedimentou o trabalho com a máscara no Brasil, o ator e diretor italiano Francesco Zigrino perfaz o sentido contrário; situa-se entre aqueles que aportaram em nosso país, para realizar cursos, oficinas, seminários e montagens que resultaram num processo que gerou continuidade. Diversos profissionais brasileiros que hoje trabalham com a linguagem da máscara tiveram contato com a pedagogia de Zigrino, concentrada na commedia dell'arte e no clown.

Formado na década de 70, na Disciplina de Arte, da Música e do Espetáculo (DAMS), pela Universidade de Bolonha, Zigrino ingressa na Escola de Jacques Lecoq em busca de uma formação prática. Originário do sul da Itália, parte em busca de um trabalho técnico, que tem referências nas experiências do pós-guerra engendradas pelo Piccolo Teatro, por Amleto Sartori, por Dario Fo e pelo próprio Jacques Lecoq entre tantos outros. $\mathrm{Na}$ escola deste último, tem a oportunidade de sistematizar uma prática que se alia aos estudos teóricos empreendidos em Bolonha. Em sua trajetória, há que ressaltar ainda a experiência de grupo; certamente, um elemento fundamental para a reflexão e prática da sua metodologia. Estabelecido em Tarando, funda, juntamente com outros artistas, um grupo de teatro, no qual exerce as funções de diretor e preparador de atores, realizando um trabalho em consonância com a população local.

No início da década de 80, Zigrino desembarca em São Paulo, inicialmente, para a apresentação de um espetáculo; posteriormente, intermediado pelo Instituto Italiano de Cul-

8 Outros espetáculos significativos do grupo foram Quem Manda na Banda (1981) e Crônica da Cidade Pequena (1984). 
tura, ministra cursos na Escola de Arte Dramática (EAD/ECA) e na Fundação Armando Álvares Penteado (FAAP), durante os quais diversos alunos têm o primeiro contato com a máscara neutra, segundo os princípios articulados por Jacques Lecoq. O pedagogo amplia sua inserção e atua como diretor e preparador de atores com as técnicas do clown e da commedia dell'arte. ${ }^{9}$ Fundamentalmente, a configuração do palhaço efetua-se mediante o jogo teatral e o improviso, estimulado pelo orientador, que veste a "máscara" do Monsieur Loyal, o "proprietário" do circo. Buscam-se, nessa relação assimétrica, os aspectos particulares do aluno que servem à composição do clown.

A experiência de Francesco Zigrino resulta num processo multiplicativo, estimulando a formação e o aprofundamento de numa quantidade expressiva de profissionais brasileiros que trabalham com a commedia dell'arte e o clown, seja como linguagem seja como instrumento para a formação e o treinamento do ator. Há que ressaltar ainda a inserção na $\mathrm{EAD}$, propondo linguagens distintas das que eram predominantes naquele momento, proporcionando uma revitalização do processo de criação teatral. É oportuno lembrar que Cristiane Paoli-Quito, uma das alunas que mantiveram contato com Zigrino, em 1983, é a atual diretora da Escola.

Os percursos trilhados pelos três profissionais caracterizam-se pela diversidade e se interseccionam em princípios comuns, muitos dos quais, lastreados direta ou indiretamente na pedagogia de Jacques Lecoq. No trabalho de cada professor, as metodologias constroem-se em conformidade com o percurso, no qual as referências são (re) trabalhadas em cada contexto. A ampla possibilidade de utilização da máscara reflete-se na prática dos professores, quando percebemos que eles não se fecham em apenas uma escolha.

A máscara não se presta somente à construção do personagem, mas apresenta-se como instrumento para a compreensão do fenômeno teatral, distanciando-se de uma perspectiva exclusivamente técnica. $\mathrm{O}$ projeto pedagógico colabora na formação do ator, e permite aguçar a percepção e a análise nesse fazer: ainda que ele não eleja a máscara como escolha artísti$\mathrm{ca}$, trabalha procedimentos que são essenciais para a compreensão do seu ofício. A dimensão que ela instaura é a própria essência do teatro e fundamenta-se na tríplice relação: do ator com ele mesmo, com o outro, e com o espectador. Nesse lugar de metamorfose - em que as certezas do ator e do espectador são postas em jogo na flexuosidade da cena -, a máscara faz apelo ao outro, e é pelo olhar desse outro que ela se constitui. Nesse fluxo contínuo que a caracteriza, jogo e improvisação integram a sua natureza, de tal modo que, embora existam princípios determinantes para a sua configuração cênica, quando posta em moção, esses princípios se relativizam.

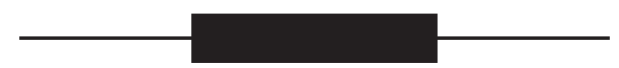

9 Zigrino monta as peças O Arranca Dentes, resultado do exercício da commedia dell'arte, empreendido pela turma de 1983, da EAD; Pinóquio, de Carlo Collodi, e Esperando Godot, de Samuel Beckett, na qual utiliza linguagem do clown. Na montagem de Você vai ver o que você vai ver, realizada pelo Circo Grafitti, atua como professor de técnica de clown. Em 2005, Zigrino retorna ao Brasil, a convite do Clã - Estudos das Artes Cômicas. 


\section{Referências bibliográficas}

HOTTIER, P. La structure du masque agit sur le corps et le mental du comédien. In: Le masque. Du rite au théâtre. Paris: CRNS, 1989. p. 235-9.

JOHNSTONE, K. Impro. Improvisation and theatre. London: Methuen, 1981.

LECOQ, J. Le corps poetique. Un enseignement de la création théâtrale. En colaboration avec Gabriel Carasso et Jean-Claude Lallias. Paris: Actes Sud-Papiers, 1997.

LOPES, E. P. A máscara e a formação do ator. Tese (Doutorado em Artes). Instituto de Artes da UNICAMP, 1991. 